\title{
Quenching Technology: A Selected Overview of the Current State-of-the-art
}

\author{
Lauralice de Campos Franceschini Canale ${ }^{\mathrm{a} *}$, George E. Totten ${ }^{\mathrm{b} *}$ \\ ${ }^{a}$ Departamento de Engenharia de Materiais, Aeronáutica e Automobilística da EESC-USP, \\ Av. Trabalhador São Carlense, 400, 13566-590 São Carlos - SP, Brazil \\ ${ }^{\mathrm{b}}$ G.E. Totten \& Associates, LLC, Seattle, WA, USA
}

Received: July 19, 2004; Revised: September 1, 2005

\begin{abstract}
Many papers have been published on a wide range of aspects of the fundamental physics and chemistry of quenching such as: additive technology, surface rewetting, hardness distribution prediction, role of heat transfer and residual stresses, etc. ${ }^{1,2}$. However, relatively little information has been published on the application of these insightful research results for the solution of long standing quench tank production problems. This paper will address three areas where technical advancements have been, or may be, made. These include discussion of: 1) the application fundamental fluid dynamics to characterize quenching uniformity due to agitation; 2) the use of "waves" to provide uniform agitation during the quenching process; and 3) the use of pressure as a variable to mediate heat transfer throughout the quenching process.
\end{abstract}

Keywords: heat treatment, quenching, quench system design, heat transfer

\section{Introduction}

Optimal quench uniformity is essential if the potential for cracking, distortion, residual stress and spotty hardness is to be minimized. This means that heat transfer during the film boiling (vapor blanket) and nucleate boiling processes during heat transfer in vaporizable liquids such as water, oil and aqueous polymers must be as uniform as possible throughout the quenching process. One of the most important factors affecting quench uniformity is the design of the quench system. Deficiencies in system design have frequently been inadequately addressed by both heat treating engineers and equipment suppliers, often with disastrous results. With the exception of a few little-known company specifications, there are no industry-wide guidelines for quench system design. Therefore, there is no extensive compilation of state-of-the-art design criteria to assist the engineer in the design and construction of a quenching system that will provide optimal heat transfer and quench uniformity.

Agitation is one of the most critical areas of system design. The effect of agitation on the performance of various quench oils has been studied in detail. Liscic reported that the ability to throughharden AISI 4135 steel in a conventional quench oil increased with increasing agitation ${ }^{3}$. Although decreasing oil temperature provided some improvement in through-hardening, it was considerably less effective than increasing agitation rate. Kweon et al. also showed that increasing agitation increased cooling rates and the through-hardening ability of both oil and water quenchants for SNCM 21 steel $^{3}$. Vivas and Tardio studied the influence of both agitation and temperature on the distortion of various carburized steels. They showed that agitation of a quench oil was necessary to destabilize film boiling and nucleate boiling processes if uniform heat transfer throughout the quenching operation was to be achieved ${ }^{3}$.

The relative efficacy of using immersion or spray quenching with an aqueous polymer and a mineral oil quenchant was studied by Moreaux et al. ${ }^{3}$. Their results showed that depth of hardness increased with increasing agitation. Moreaux et al. also showed that the as-quenched hardness of a complex part quenched in either an aqueous polymer or a mineral oil was highest for the portion of the part subjected to the greatest agitation. These data clearly showed that proper racking to ensure optimal uniformity of quenchant flow around all surfaces is necessary.

Propeller agitation of both oil and water under commercial quenching conditions has been reported to significantly improve quench uniformity, producing less cracking and distortion ${ }^{3}$. Khavskii and Zelokovtseva proposed that cracking and deformation are predominantly affected by the uniformity of the quench and not the quenchant itself ${ }^{4}$. Thus, the design of the agitation system for a particular process is perhaps the largest single contributor to the uniformity of the quench process.

Quench severity is dependent on agitation rate, size of the tank, fluid viscosity, type and placement of agitators, and other variables. Agitation clearly affect the hardness and depth of hardening during the quench because of the mechanical rupture of the relatively unstable film boiling cooling process that typically occurs in vaporizable quenchants such as oil, water, and aqueous polymers. However, other variables such as fluid viscosity and vapor pressure of the fluid are clearly important as well.

This paper will address three areas where technical advancements have been, or may be, made. These include discussion of: 1) the application fundamental fluid dynamics to characterize quenching uniformity due to agitation ${ }^{5}$; 2) the use of "waves" to provide uniform agitation during the quenching process; and 3) the use of pressure as a variable to mediate heat transfer throughout the quenching process.

Quenching is often refereed to as the "black hole" of heat treating. In many heat treating shops, there is only minimal understanding of the quenching process itself. There have been number of recent publications interrelating various fundamental principles involved in quenching such as surface wetting, a physical chemical phenomenon, and heat transfer with as -quenched metallurgical properties such as hardness and distortion ${ }^{1}$. However, relatively little information is available integrating the importance of both organic and physical chemistry of the quenchant in achieving the desired metallurgical result. 


\section{Discussion}

\subsection{Use of computational fluid dynamics (CFD) in quench system design}

Quench severity is agitation dependent. Therefore, magnitude and turbulence of fluid flow around a part in the quench zone is critically important relative to the uniformity of heat transfer throughout the quenching process ${ }^{6-10}$. One of the greatest contributors to non-uniform hardness, increased thermal stresses, racking and distortion is nonuniform fluid flow throughout the quench zone in production quench tanks ${ }^{11}$. The impact of non-uniform flow is increased distortion and cracking. It is critically important to optimize the uniformity of fluid flow in the quench zone to provide optimum control of distortion and to minimize cracking ${ }^{12,13}$.

Some of the classic methods of measuring fluid flow on both a laboratory and commercial scale include: turbine velocimeters ${ }^{16}$, streak photography ${ }^{14,15}$, pitot-static tube ${ }^{17}$, electromagnetic current meter $^{18}$, hot-film anemometer ${ }^{14}$, and laser Doppler velocimetry ${ }^{14,16}$. Figure 1 illustrates the use of streak photography conducted on an model of a quench tank for an integral quench furnace (also known as a sealed quench furnace (SQF).) The results, shown in Figure $1^{15}$, illustrated the non-uniform flow fields in the tank even before a load was introduced. However, these methods are generally unsuitable for continuously monitoring fluid flow in commercial quench tanks during heat treat processing and although they have provided invaluable insight into the fluid mechanics of the quenching process, they are of limited value from the standpoint of design and simulation of new systems.

Computational fluid dynamics (CFD) modeling is being increasingly used to examine the uniformity of fluid flow in a quench tank. Totten and Lally (see Figure 2) reported one of the first examples of the application of this methodology to illustrate the non-uniformity of quench tank fluid flow ${ }^{16}$. Garwood et. al. performed similar, but much more rigorous work with model validation on an actual commercial quench system as illustrated in Figure $3^{18,19}$ with subsequent model validation.

Bogh used CFD analysis to examine the impact on quench non-uniformity of the placement of submerged spray eductors at various locations around a rack of aluminum panels. Examples of two of the models illustrated by Bogh are shown in Figure $4^{20}$. More recently, Halva and Volny ${ }^{21}$ have used CFD analysis to examine the homogeneity of fluid flow as a function of agitator placement. An example of their flow model is provided in Figure 5. An example of the use of CFD modeling to design quench system with improved flow uniformity can be find in the reference ${ }^{22}$. Examples of two flow configurations using impeller stirrers are shown in Figure 6.

A study was sponsored by SAE - AMEC Committee to evaluate the concentration limitations to meet Mil. Handbook 5 design minimums for Type I quenchants for aluminum heat treating standard development. Unfortunately, the results were too scattered to achieve the desired goal. CFD analysis was performed which illustrated the variance in physical property data was likely due to flow velocity variation in the quench tank as shown in Figure $7^{23}$.

CFD modeling has been conducted on a classic laboratory apparatus used for cooling curve analysis. The results of this work showed that even this system was susceptible to significant flow variation in the quench zone which would lead to large variations in cooling curve results ${ }^{24}$.

Recently CFD analysis was conducted with the objective of obtaining an understanding of the flow in an existing quench tank and to use these results to provide innovative design concepts for a new quench system design. The performance of the various designs evaluated was determined using Taguchi partial factorial statistical analysis methodology and this data was used to simulate fluid flow in the design of a commercial quench tank ${ }^{25}$.

In summary, a literature survey has clearly illustrated the enormous potential in improving quenching performance in the workshop by utilizing CFD analysis. This methodology can be used to analyze fluid flow in existing quench tanks with the objective of retrofitting for

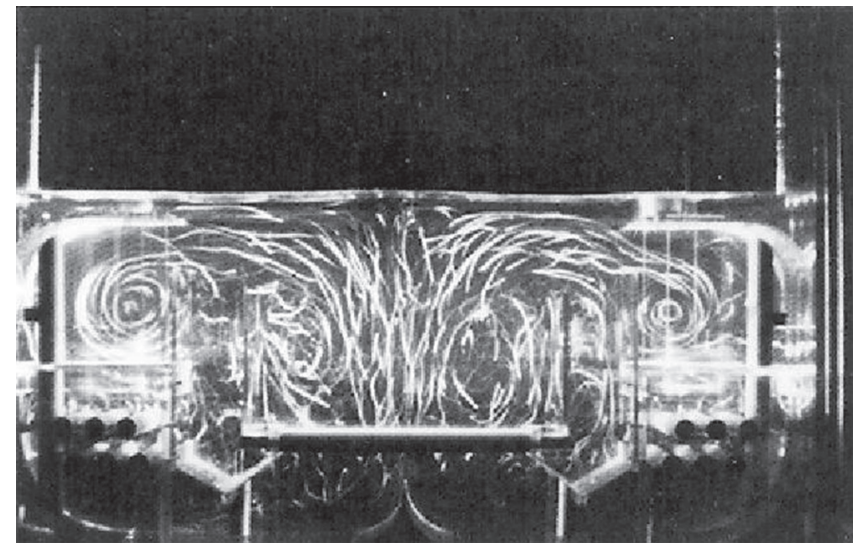

Figure 1. Streak photography of an unloaded quench tank for a SQF.

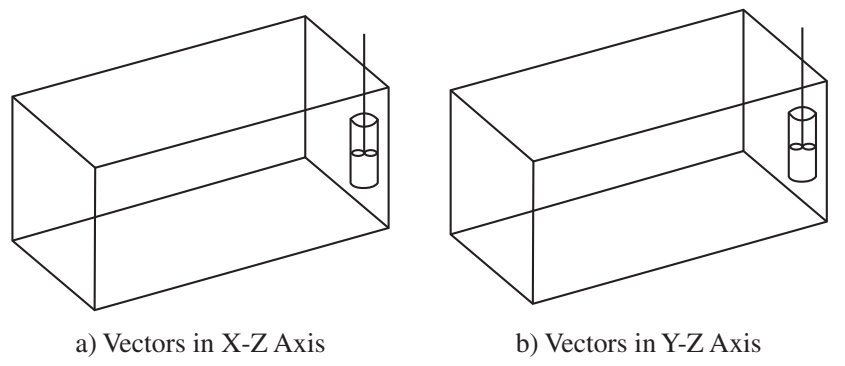

Figure 2. CFD prediction of 3-D flow in a quench tank with a single cornermounted impeller stirrer, a) Vectors in the $\mathrm{x}-\mathrm{z}$ axis; and $\mathrm{b}$ ) vectors in the y-axis.

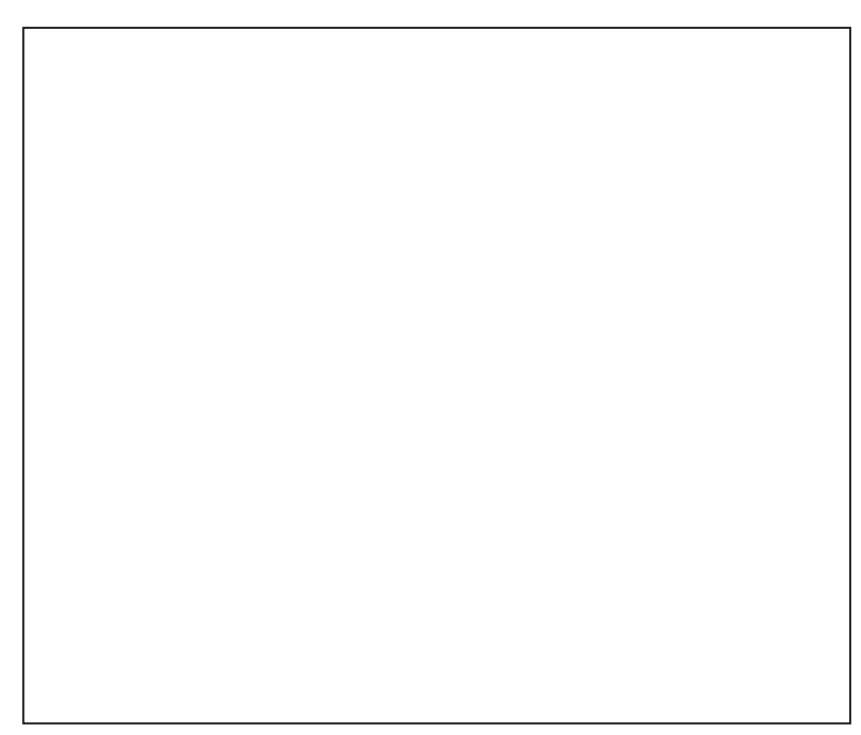

Figure 3. Illustration of the Garwood, et al. model of a deep rectangular tank with propeller agitators in each of the four corners. 


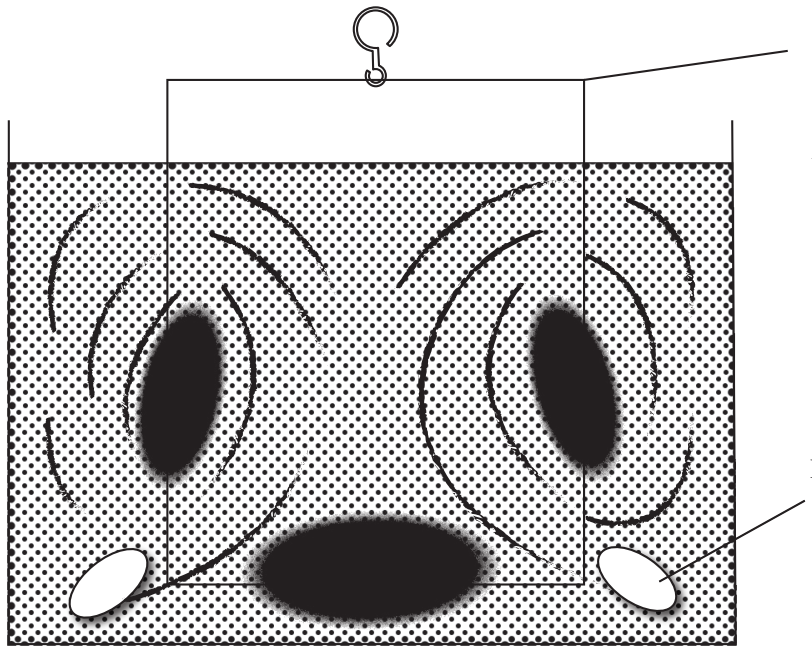

(a)

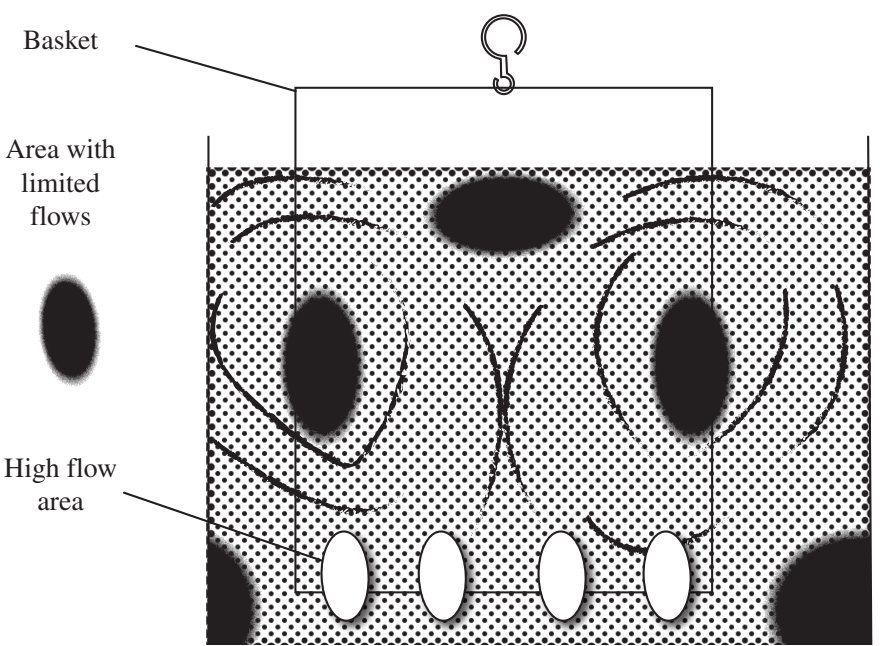

(b)

Figure 4. Effect of spray eductor placement on quench uniformity, a) Eductors placed at opposite bottom edges; and b) Eductors placed directly under the load.

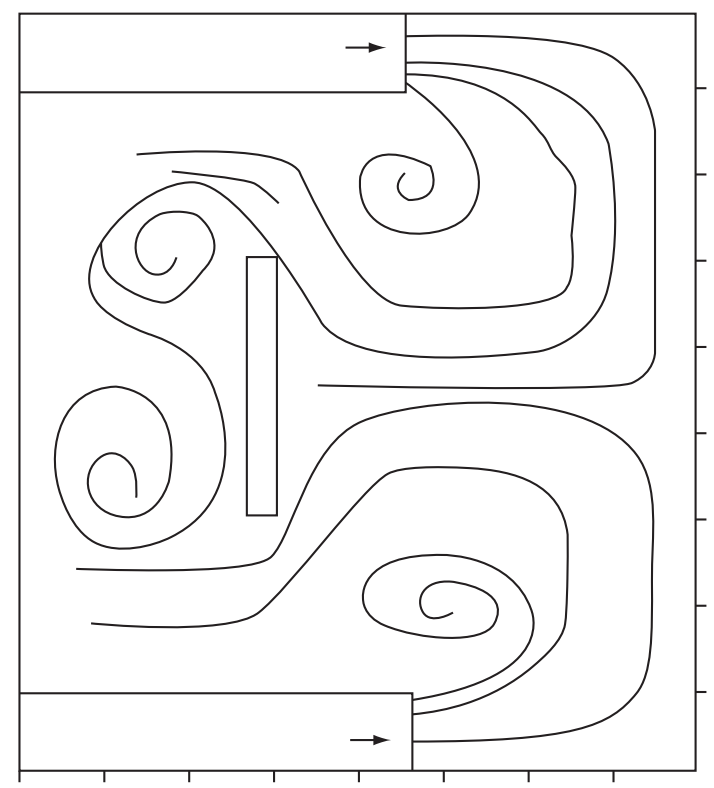

Figure 5. Halva and Volny model of quench tank flow uniformity (Adapted from reference $)^{5}$.

improved performance or it can be used to design new and innovative quench systems with the objective of optimizing quenching performance for distortion control and reduction of cracking problems.

\subsection{Quenching with waves}

It has been shown that very high agitation rates using pump and impeller systems, when properly designed, can provide maximum compressive stresses and substantial reductions in cracking and improved distortion control ${ }^{27,28}$. One of the advantages of such processes, designated as "intensive quenching" processes, is that water or brine can be used to replace toxic and flammable petroleum-based quench oil. Although impeller and pump agitation systems can be used, it is still mandatory that uniform flow fields around part being quenched be provided which can be particularly problematic as with non-intensive quenching systems. Table 1 illustrates the increased
Table 1. Quench Severity Achieved with Different Modes of Agitation.

\begin{tabular}{lc}
\hline \multicolumn{1}{c}{ Quenchant } & Grossman H-Value (in-1) \\
\hline Oil & \\
Still Quench & $0.25 / 0.30$ \\
Violent Agitation & $0.80 / 1.10$ \\
Ultrasonic Agitation & 1.65 \\
Brine & \\
Still Quench & 2.0 \\
Violent Agitation & 5.0 \\
Ultrasonic Agitation & 7.5 \\
Hot Salt (400 ${ }^{\circ}$ F) & \\
Still Quench & 0.30 \\
Violent Agitation & 1.20 \\
Ultrasonic Agitation & 1.80 \\
\hline
\end{tabular}

quench severity relative to "violent" impeller agitation that can be achieved by ultrasonic agitation ${ }^{26}$.

Various workers have shown that water can be successfully used to replace quench oil with a corresponding and often dramatic reduction of cracking when agitation is supplied by ultrasonics or electric or magnetic fields ${ }^{26}$. Khavskii and Zelokhovtseva have attributed this success to the substantial improvement in uniformity of the cooling process by uniformly rupturing the film blanket that surrounds the hot metal parts immediately upon immersion ${ }^{4}$. It is this unstable vapor blanket that often leads to distortion control and cracking problems.

Recently, Sverlin, et. al. Reported that the use of "wave technology" which is based on non-linear oscillations of liquid-gas-solid particle-based quench systems (provided by "vibromixing")provide superior mechanical properties while minimizing distortion control and cracking problems ${ }^{29}$. Vibromixing is achieved by circulating the quenching medium in a closed circuit using a hydraulic pump which then passes through a generator where the kinetic energy of the fluid is transformed into vibrational energy in the cooling zone. The influence of vibration frequency on cooling behavior was studied using a $30 \mathrm{~mm}$ dia. X $60 \mathrm{~mm}$ cylindrical stainless steel $(12 \mathrm{X} 18 \mathrm{H} 10 \mathrm{~T})$ probe and the results are illustrated in Figure $8^{29}$. The quenching medium was distilled water at room temperature. These 


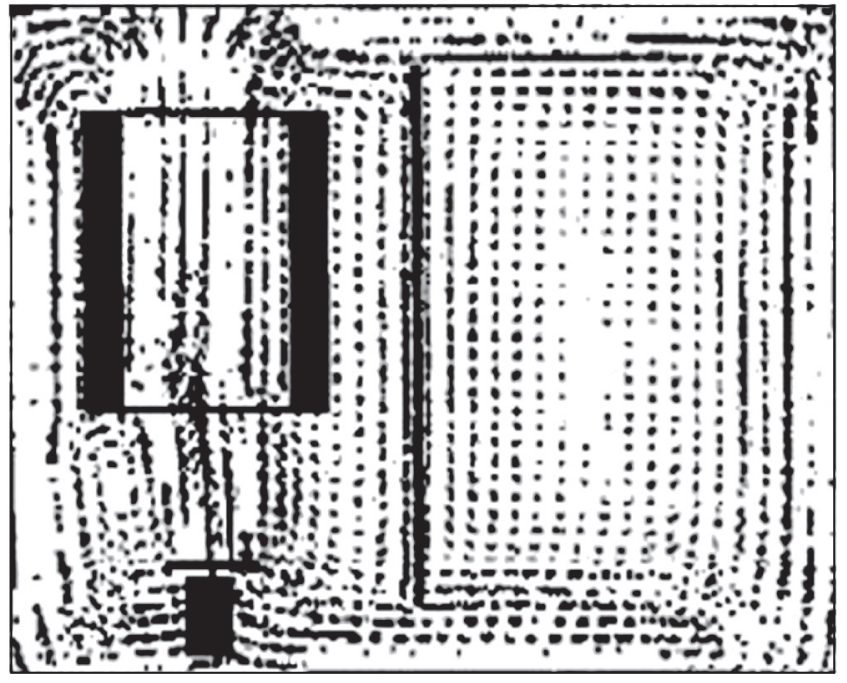

(a)

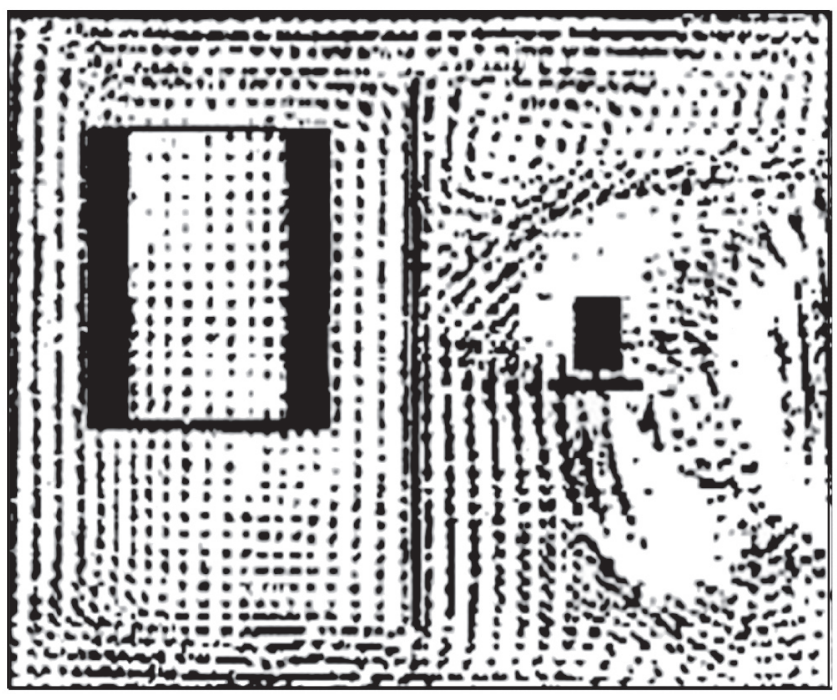

(b)

Figure 6. a) Effect of side-entering impeller stirrer adjacent to the load; and b) Illustration of the use of flow-directing baffling to improve flow uniformity.

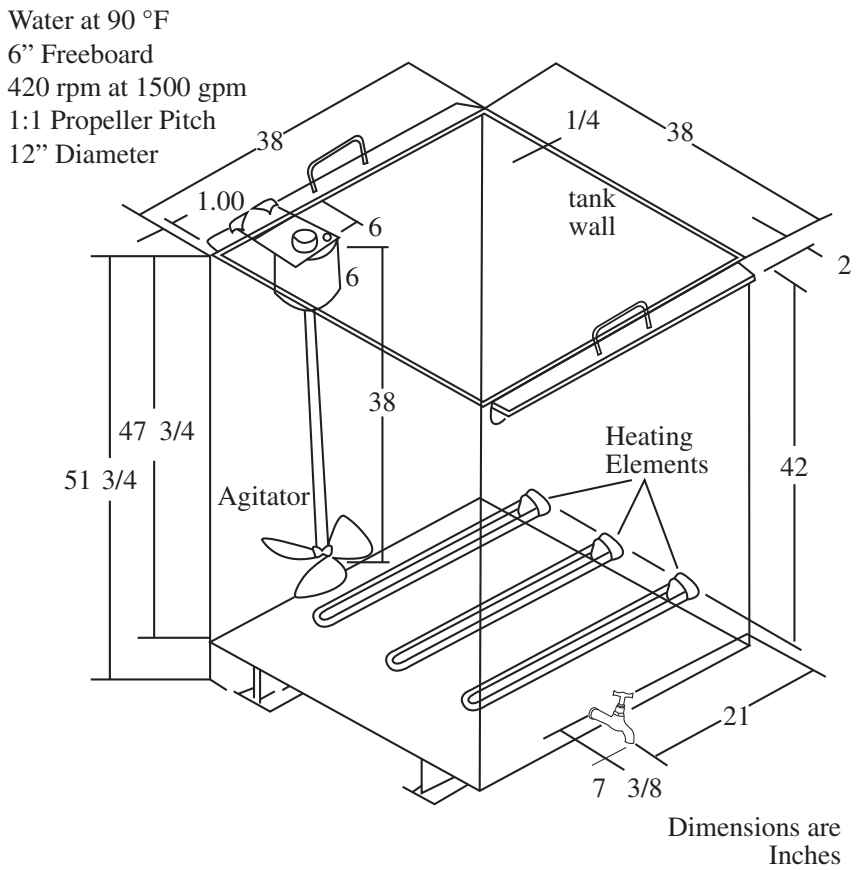

(a)

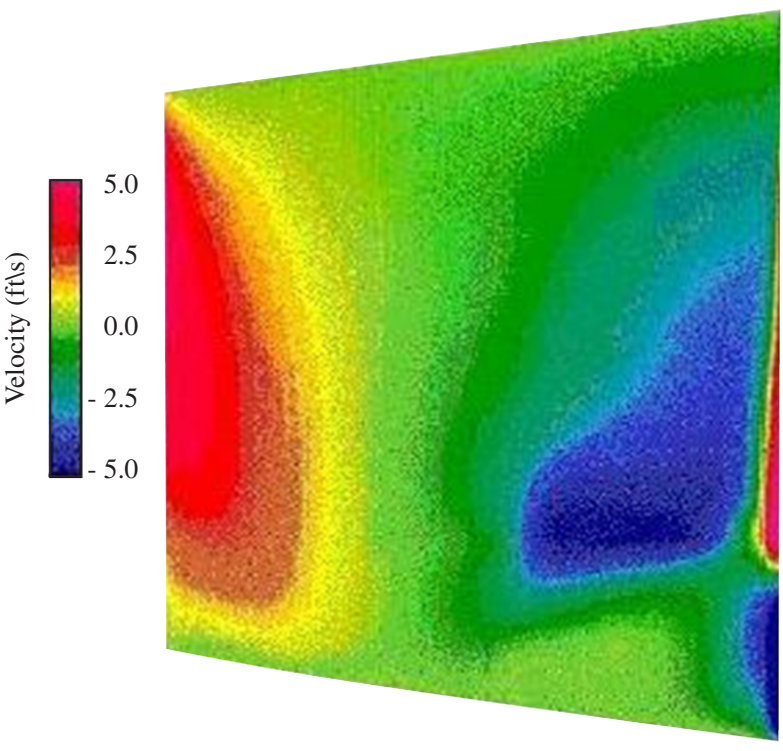

(b)

Figure 7. Flow velocity variation in a quench tank used for a SAE-AMEC quenchant study.

results show that cooling rate is dependent on the vibration frequency, which can potentially be varied during the quenching process, and therefore vibration frequency can be used to control the mechanical properties obtained.

\subsection{Effect of boiling point and surface pressure on quench oil performance}

In addition to oil viscosity, the boiling point of a quench oil is a critically important characterization parameter. It is known that the boiling point of a quench oil affects the timing of the transitions from film boiling to nucleate boiling and from nucleate boiling to convective cooling. The boiling point of a petroleum oil can be reasonably modeled by ideal gas law characteristics and one equation that has been reported which can be used to estimate boiling point is ${ }^{30}$ :

$$
\log _{10} \mathrm{P}=\mathrm{A}-\mathrm{B} /(\mathrm{C}+\mathrm{T})
$$

where: $\mathrm{P}=$ pressure $(\mathrm{kPa}), \mathrm{T}=$ temperature $\left({ }^{\circ} \mathrm{C}\right)$ and $\mathrm{A}, \mathrm{B}$ and $\mathrm{C}$ are constants.

Yokota has studied the effect of the volatility (boiling range) of petroleum base stocks on quenching performance ${ }^{31,32}$. It was shown that the "cooling power" of an oil quenchant was dependent on the cooling rate in the $300-350{ }^{\circ} \mathrm{C}$ temperature range as measured by JIS K 2242 silver probe cooling curve analysis method (see Figure $9^{31}$ ). Typically, the 5\% distillation temperature of petroleum oil base stocks 


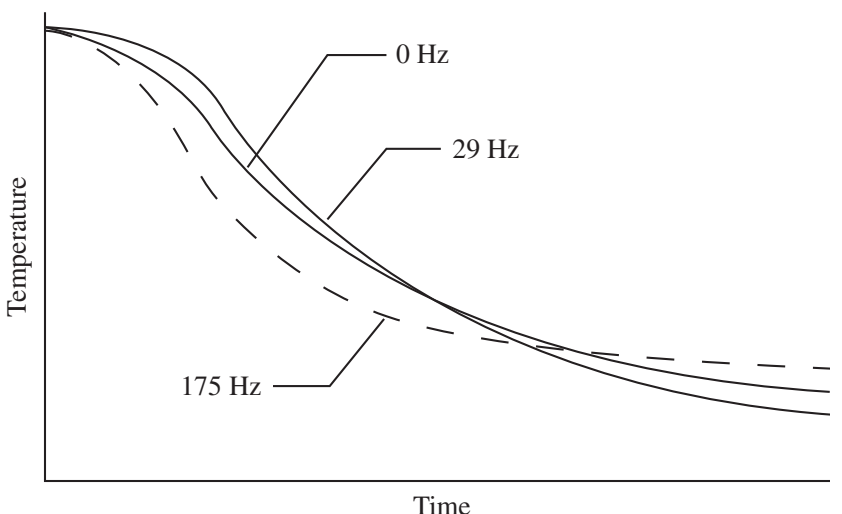

(a)

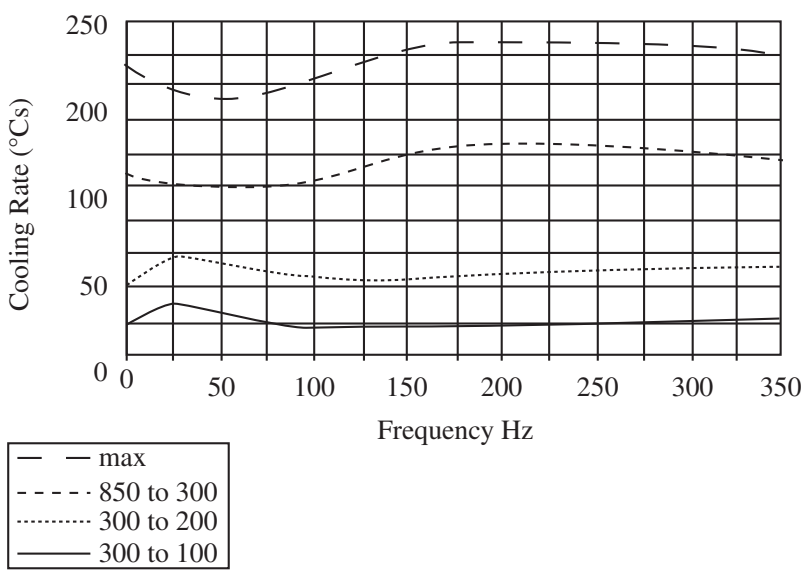

(b)

Figure 8. Illustration of the effect of vibrational frequench on: a) Cooling curve behavior of distilled water; and b) On the cooling rate as a function of vibrational frequency.

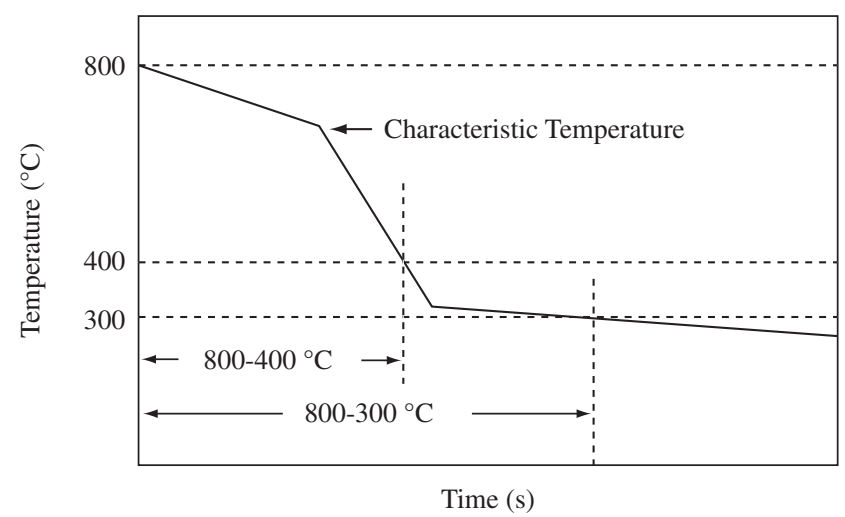

Figure 9. Illustration of important characteristic temperatures for cooling curves obtained by the JIS K 2242 silver probe method.

could be correlated with cooling rates in this range which, in turn, affected hardness, as shown in Figure $10^{32}$ and distortion. In general, hardness and distortion increased with oil volatility. However, it was also shown that by reducing the surface pressure of a higher viscosity basestock would exhibit nearly equivalent hardness with less distortion than is achievable with a lower viscosity basestock.

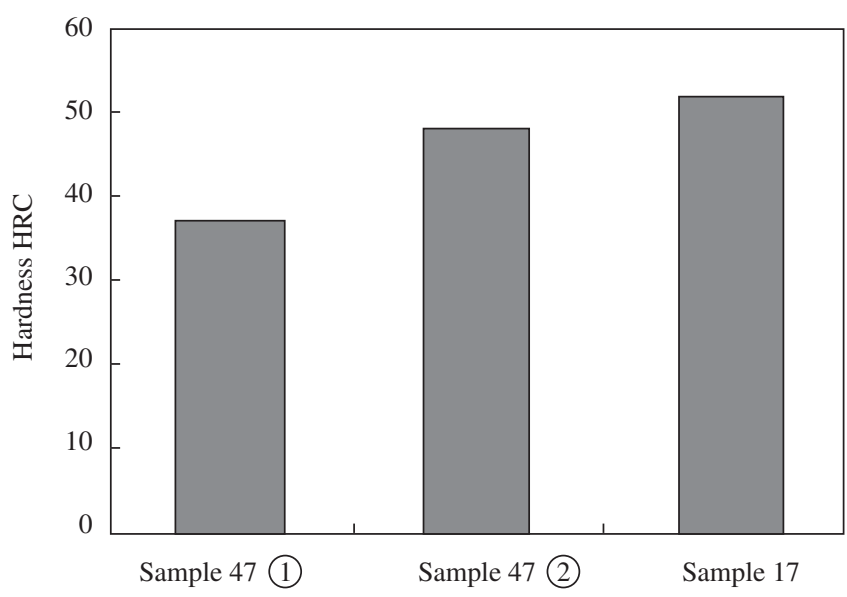

(a)

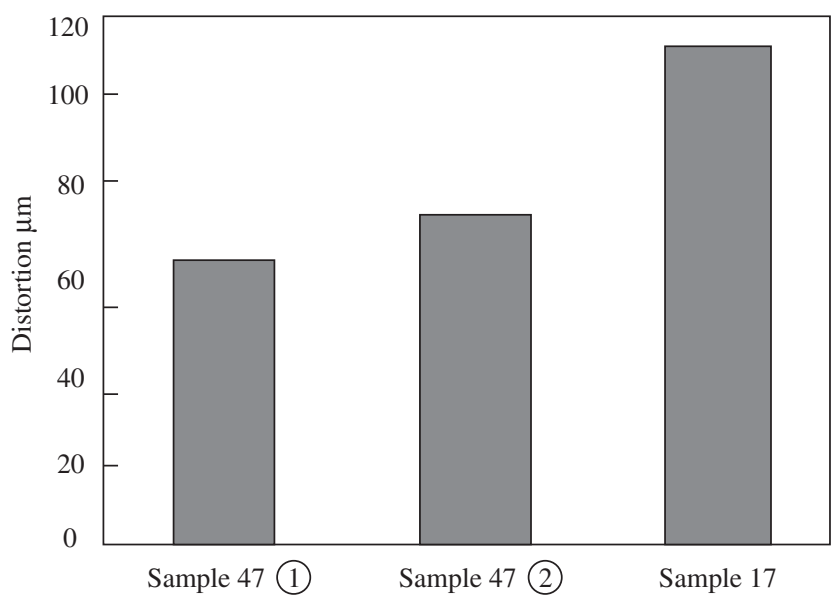

(b)

Figure 10. High-viscosity oils: Sample 47(1) 5\% distillation temperature $<350{ }^{\circ} \mathrm{C}\left(47 \mathrm{~mm}^{2} / \mathrm{s}\right)$, Sample $47(2) 5 \%$ distillation temperature $>350{ }^{\circ} \mathrm{C}$ $\left(47 \mathrm{~mm}^{2} / \mathrm{s}\right)$ and Sample $17\left(17 \mathrm{~mm}^{2} / \mathrm{s}\right)$ : a) As-quenched hardness comparison of the three quench oils; and b) Quenching distortion obtained with the three quench oils.

Asada and Ogino showed that it is possible to increase cooling speeds by reducing the surface pressure of the quenching oil as illustrated in Figure $11^{33}$. This process substantially improves the surface uniformity of the cooling process by facilitating the uniform rupture (destabilizing) the vapor film that is formed around the hot metal part upon immersion.

Ichitani examined this process still further and developed two processes: 1. "Decompression-Pressure Recovery Control Method" where the vapor film that is formed initially is stabilized by decompression and then ruptured completely and simultaneously by a "recovering pressure" and 2. "Atmospheric Pressure-Decompression Control" where the part is quenched into the oil at atmospheric pressure and after the vapor film ruptures, the surface pressure is decreased. This process produces higher hardness while minimizing distortion and permitted the use of a high-viscosity oil with a broader boiling point range ${ }^{30}$. 


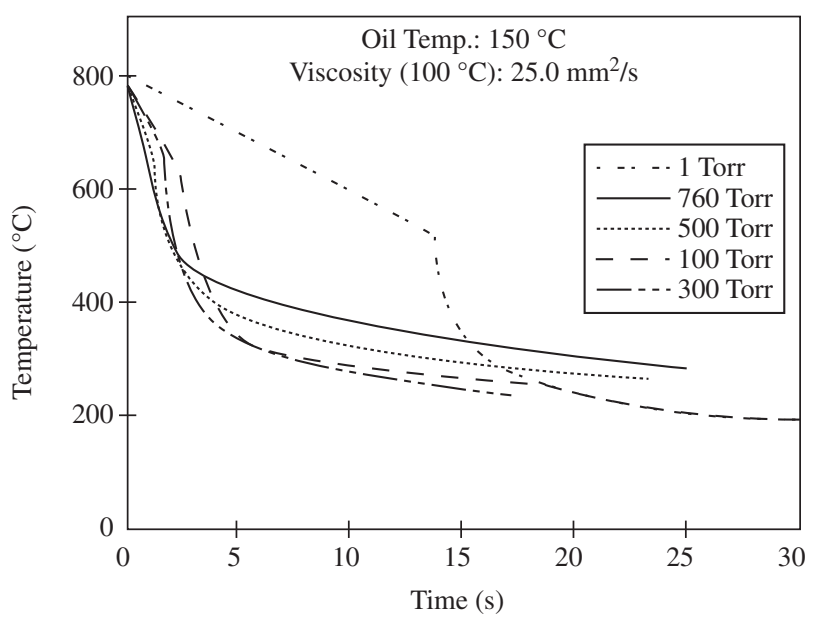

Figure 11. Cooling curve performance of a martempering oil under reduced pressure using the JIS K 2242 cooling curve analysis method.

\section{Conclusion}

In this discussion three relatively new and important developments in quench system engineering were discussed. The first was the use of CFD analysis to examine fluid flow in existing quench tanks and to simulate innovative and improved advanced quench system designs. The advantage of CFD analysis is that system analysis can performed without first building prototype systems.

The second development, although not necessarily new but still not widely known and utilized, is the idea of quenching in high intensity agitation systems using ultrasonics, magnetic fields or even vibratory mixing. These systems provide for maximum surface compressive stresses with minimal distortion relative to high intensity sprays and impeller agitation.

The third development that was discussed was recent work that has been conducted to provide for continuous control of quench severity and for providing optimal quench uniformity by varying the surface pressure of quench oils during quenching. This approach yield significant improvements in as-quenched hardness while simultaneously providing for optimal improvements in distortion reduction of critical parts during quenching.

\section{References}

1. Tensi HM, Totten GE, Canale LCF. The quenching process: an overview of the fundamental physical properties of liquid quenching. Proceedings of the 58 $8^{\text {th }}$ Congresso Anual da ABM; 2003 July 21-24; Rio de Janeiro, Brazil. São Paulo: ABM Brazil; 2003. p. 3362-3380.

2. Totten GE, Tensi HM, Canale LCF. Chemistry of quenching: part 2 - fundamental thermophysical processes involved. In: quenching. Proceedings of $22^{\text {nd }}$ Heat Treating Society Conference and the $2^{\text {nd }}$ Surface Engineering Congress; 2003 September 15-17; Indianapolis, USA. Materials Park, OH: ASM International; 2003. p. 148-155.

3. Totten GE, Bates CE, Clinton NA. Quenching system design. In: Totten, GE, Bates CE, Clinton NA. editors. Handbook of Quenchants and Quenching Technology. Materials Park, OH: ASM International; 1993. p. 339-411.

4. Khavskii NN, Zelokhovtseva RR. Provision of optimum cooling conditions during quenching of steel. Izv. V.U.Z. Chernaya Metall. 1982; 3:111-113.

5. Tensi HM, Totten GE, Webster GM. Proposal to monitor agitation of production quench tanks. In: Milam D, Poteet D, Pfaffmann G, Albert W, Muhlbauer A, Rudnev, V. editors. Proceedings of $17^{\text {th }}$ Heat Treating
Society Conference Proceedings Including the 1st International Induction Heat Treating Symposium. Materials Park, OH: ASM International. 1997. p. $423-431$.

6. Totten GE, Webster GM, Gopinath N. Quenching fundamentals: effect of agitation. Adv. Mat.\& Proc. 1996; 149(2):73-76.

7. Olivier J, Clement B, Debie JJ, Moreaux F. Stirring of quenchants fluids: design considerations and metallurgical consequences. Trait. Therm. 1986; (206):29-42.

8. Anon, function of proper agitation in quenching to assure uniform physical properties. Ind. Heat. 1979; January: 14-17.

9. Bergmann HR. Importance of agitation for optimum quenching. Metals Eng. Quart. 1971; 11(2):17-19.

10. Anon, tensiles and yields are closer with fast circulation of quench oil. Metal Treat. 1964-1965; December-January: 18-19.

11. Improved quenching of steel by propeller agitation, U.S. Steel Brochure, Pittsburgh, PA, USA; 1954.

12. Von Bergen RT. The Effects of Quenchant Media Selection and Control of the Distortion of Engineered Steel Parts. In: Totten GE editor. Proceedings of Conf. Quenching and Distortion Control. Materials Park, OH: ASM International; 1992. p. 275-292.

13. Kern R. Distortion and Cracking. III. How to control cracking. Heat Treat. 1985, April; 27(4):38-42.

14. Oldshue JY. In: Fluid Mixing Technology. New York, NY: McGraw-Hill; 1983. p. 162-168.

15. Segerberg $\mathrm{S}$. Controlling the quench process for more consistent hardening Heat Treat. 1988, May; 20(5):26-28.

16. Totten GE, Bates CE, Clinton NA. Impeller Agitation. In: Totten GE, Bates CE, Clinton NA, editors. Handbook of Quenchants and Quenching Technology. Materials Park, OH: ASM International; 1993. p. 413-439.

17. Bates CE, Totten GE, Brennan RL. Quenching of steel. In: ASM editor. Handbook, Vol. 4: Heat Treating, Materials Park, O: ASM International; 1991. p. 67-120.

18. Garwood DR, Lucas JD, Wallis RA, Ward J. Modeling of flow distribution in an oil quench tank. Journal Mat. Eng. And Perf. 1992; 1(6):781-786.

19. Wallis RA, Garwood DR, Ward J. The use of modeling techniques to the quenching of components. In: Totten, G.E, Wallis, R.A editors. Heat Treating: Equipment and Processes - 1994. Conference Proceedings. Materials Park, OH: ASM International; 1994. p. 105-116.

20. Bogh N. Quench tank agitation design using flow modeling In: Totten GE, Wallis RA. Heat Treating: Equipment and Processes. 1994. Conference Proceedings. Materials Park, OH: ASM International; 1994. p. 51-54.

21. Halva J, Volny J. Modeling the Flow in a Quench Bath. Hutnicke Listy. 1993; 48(10):30-34.

22. Anon, L'agitation submersible Au coeur des bacs de trempe. Trait. Therm. 1994; 278:73-75.

23. Scott MD, Totten GE, Gopinath N. CFD Modelling of Quench Tank Agitation. In: Bell T, Mittemeijer EJ editors. Proceedings of the $10^{\text {th }}$ Congress of the IFHT. London: IOM Communications Ltd; 1999. p. 655-669.

24. Baker AJ, Manhardt PD, Orzechowski JA. On An FEM Platform for Simulation of Heat Treating Operations. In: Totten GE, Funatani K, Howes MAH, Sjostrom S. editors. Proceedings of ${ }^{2 n d}$ International Conference on Quenching and Control of Distortion. Materials Park, OH: ASM International; 1996. p. 283-290.

25. Kernazhitskiy SL. Numerical modeling of a flow in a quench tank, M.S.Thesis, 2003, Portland State University, Portland, OR, USA; 2003.

26. Totten GE, Bates CE, Clinton NA. Other Quenching Processes. In: Totten GE, Bates CE, Clinton NA. editors. Handbook of Quenchants and Quenching Technology. Materials Park, OH: ASM International; 1993. p. 291-338.

27. Totten GE, Canale LCF, Kobasko NI, Powell, JA, Aronov MA. Têmpera intensiva: levantamento histórico de um processo usualmente desconhecido, SAE Technical Paper Paper Number 2002-01-3398, São Paulo, Brazil, 2002. 
28. Kobasko NI, Aronov MA, Canale LCF, Totten GE. Metallurgy of intensive quenching process and implications with respect to steel properties. proceedings of the $58^{\text {th }}$ Congresso Anual da ABM; 2003 July 21-24; Rio de Janeiro, Brazil. São Paulo: ABM Brazil; 2003. p. 3362-3380.

29. Sverdlin AV, Ness AR, Ganiev RF. Hardening of steel parts using wave technology. In: Milam D, Poteet D, Pfaffmann G, Albert W, Muhlbauer A, Rudnev V. editors. Proceedings of $17^{\text {th }}$ Heat Treating Society Conference Proceedings Including the 1st International Induction Heat Treating Symposium. Materials Park, OH: ASM International; 1997. p. 33-39.

30. Ichitani K. Improvement of Distortion by Pressure Control Oil Quenching. In: Chinese Heat treatment Society editor. Proceedings of $4^{\text {th }}$ International Conference on quenching and the Control of Distortion; 2003, November 23-24: Beijing, China. Beijing: Chinese Heat Treatment Society; 2003. p. $437-442$.
31. Yokota H, Hoshino H, Satoh S, Kanai R. Effect of boiling range of mineral base stocks on quenching of $0.45 \%$ carbon steel. In: Funatani K, Totten GE. Heat treating. Proceedings of the 20th Conference of Heat Treating v.2, 2000, October 9-12. Materials Park, OH: ASM International; 2000. p. $827-832$.

32. Yokota H, Suda S, Hoshino H, Narazaki M, Wakabayashi T. Effect of boiling point of mineral base stocks on workpiece hardness. In: Chinese Heat treatment Society editor. Proceedings of $4^{\text {th }}$ International Conference on quenching and the Control of Distortion; 2003, November 23-24: Beijing, China. Beijing: Chinese Heat Treatment Society; 2003. p. 227-231.

33. Asada S, Ogino M. Reduced pressure quenching oil and distortion. In: Totten GE, Funatani K, Howes MAH, Sjostrom S. Proceedings of $2^{\text {nd }}$ International Conference on Quenching and Control of Distortion. Materials Park, OH: ASM International; 1996. p. 395-399. 